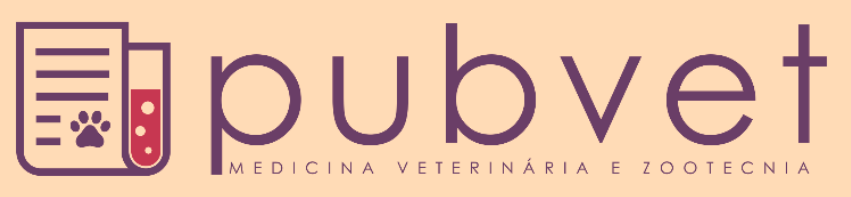

https://doi.org/10.31533/pubvet.v14n5a569.1-13

\title{
Gestão na suinocultura: um conceito holístico
}

\author{
Lívia Terezinha Soares de Castro $^{\circ}{ }^{\circ}$, Lívia Maria dos Reis Barbosa ${ }^{\circ}$, Bruno da Silva de Vasconcelos $^{30}$ \\ ${ }^{1}$ Discente de Especialização, Programa de Pós-Graduação em Gestão e Produção de Suínos, Faculdade de Ciência e Tecnologia de Viçosa \\ (UNIVIÇOSA), Viçosa, MG, Brasil. \\ ${ }^{2}$ Discente de Doutorado, Programa de Pós-Graduação em Zootecnia, Universidade Federal de Viçosa, Viçosa, MG, Brasil. \\ ${ }^{3}$ Médico veterinário, responsável pelo setor de suinocultura da Universidade Federal Rural do Rio de Janeiro, Seropédica, RJ, Brasil. \\ *Autor para correspondência, E-mail: liviasoarescastro@gmail.com
}

Resumo. Na indústria suinícola tecnificada, a gestão da informação deve ocupar papel central na tomada de decisões, envolvendo métodos gerenciais criteriosos, acompanhamento preciso das informações, implementação de correções e gestão de pessoas. Diante disso, o planejamento da produção, a definição da meta e o plano de ação são pontos de partida no gerenciamento. Portanto, a adequada gestão da atividade suinícola, requer levantamento de dados, para transformar em informação, para assim definir os objetivos, potencialidades com os recursos disponíveis. Nesta revisão, objetivou-se abordar as boas práticas na gestão da produção de suínos com vistas à sustentabilidade do negócio, melhoria da eficiência produtiva e da lucratividade, enfatizando conceitos importantes e suas aplicações práticas.

Palavras chave: gestão, informação, suinocultura, pessoas

\section{Information management in pig farming: A holistic concept}

Abstract. In the technical swine industry, information management should play a central role in decision-making, involving careful management methods, accurate monitoring of information, implementation of corrections and people management. Given this, production planning, goal setting and action plan are starting points in management. Therefore, the proper management of pig activity requires data collection, to transform into information, in order to define the objectives, potentialities with available resources. This review aimed to address the best practices in pig production management with a view to business sustainability, improvement of productive efficiency and profitability, emphasizing important concepts and their practical applications.

Keywords: management, information, pig farming, people

\section{Gestión de la información en la cría de cerdos: un concepto holístico}

Resumen. En la industria porcina técnica, la gestión de la información debe desempeñar un papel central en la toma de decisiones, involucrando métodos de gestión cuidadosos, monitoreo preciso de la información, implementación de correcciones y gestión de personas. Dado esto, la planificación de la producción, el establecimiento de objetivos y el plan de acción son puntos de partida en la gestión. Por lo tanto, el manejo adecuado de la actividad porcina requiere la recopilación de datos, para transformarse en información, con el fin de definir los objetivos, las potencialidades con los recursos disponibles. Esta revisión tuvo como objetivo abordar las mejores prácticas en la gestión de la producción porcina con miras a la sostenibilidad empresarial, la mejora de la eficiencia productiva y la rentabilidad, haciendo hincapié en conceptos importantes y sus aplicaciones prácticas.

Palabras clave: gestión, información, cría de cerdos, personas 


\section{Introdução}

A suinocultura brasileira ocupa lugar de destaque no cenário do agronegócio mundial, respondendo pela quarta maior produção e exportação de carne suína (ABPA, 2018). Além disso, passou a ser referência no emprego de novas tecnologias nas áreas de melhoramento genético, nutrição, sanidade e manejo, alavancando a produtividade e consequentemente, melhorando a margem de lucro do produtor (Sebrae, 2016). Entretanto, o emprego de novas tecnologias requer, proporcionalmente, o conhecimento da gestão da produção, garantindo a eficiência, a competividade e a sustentabilidade do setor suinícola Silva, (2015).

Até os anos 70, o sistema de criação de suínos no Brasil era voltado especialmente para a subsistência, com foco na produção de banha, por sua vez muito utilizada na elaboração e conservação de alimentos, e ocorrendo comercialização apenas da produção excedente (Serafini et al., 2019; Zen et al., 2014). Esse sistema é conhecido como produção extensiva, definida como extrativista e de subsistência, praticamente sem controle de dados e manejos (Machado \& Dallanora, 2013). Segundo esses autores, a suinocultura de subsistência com baixa tecnificação apresenta uma tendência de desaparecimento, sendo substituída pelo sistema intensivo, com alto nível tecnológico e maior produtividade. Na suinocultura cada vez mais tecnificada, o modelo de gestão deve exigir análise minuciosa dos dados zootécnicos, extrapolações econômicas desses dados e, acima de tudo, uma visão global de todo o processo de produção, dentro e fora da granja (ABCS, 2013). No entanto, apesar do avanço em termos zootécnicos, não houve uma evolução significativa do modelo e do método de gerenciar os negócios, tornando-se um ponto crítico e limitante para a melhoria do resultado econômico da atividade (Carvalho, 2016).

A gestão da informação envolve todos os conceitos de gestão, incluindo: planejamento, organização, estruturação, processamento, controle, avaliação e tomada de decisão (Duarte et al, 2007). Esses conceitos permitem que a informação seja gerada e repassada para o produtor, colaboradores e envolvidos no processo de produção através das mesmas, serão capazes de orquestrar um plano de ação, considerando a real situação e as metas a serem atingidas (Agroceres, 2016).

O primeiro passo na gestão de uma granja começa com a definição da meta de produtividade, uma visão clara de futuro (Agriness, 2016), tendo como base outros sistemas de produção similares (benchmarking), além de, considerar o nível tecnológico e recursos utilizados no processo (ABCS, 2013). Portanto, é no planejamento que as metas são estabelecidas e é através delas, que se consegue explorar o máximo potencial de produção da granja (Agroceres, 2016). Dentro desse cenário, a informação tornou-se a matéria-prima para o crescimento da suinocultura brasileira (Agriness, 2016). Pois, o processo de gestão envolve o conhecimento e o controle dos dados, gerando a informação necessária para o estabelecimento de metas e tomada de decisão (Silva, 2015). É preciso ressaltar a importância das pessoas envolvidas em todo sistema, em destaque os gestores e os colaboradores, pois são fundamentais para que a operação aconteça (Agroceres, 2016). O mundo exige dos gestores dinamicidade, soluções rápidas e eficazes dos problemas (Kruger et al, 2009).

Diante do exposto, objetivou-se com este artigo, apresentar e discutir a gestão da informação na suinocultura, abordando conceitos de gestão e sua evolução, modelos ou ferramentas de gestão, gestão de pessoas e gestão estratégicas dos custos.

\section{Conceitos e teorias da gestão}

O termo gestão muitas vezes é confundido com administração, o que leva muitos a compreendê-los como sinônimos (Dias, 2002). Drucker (1975) ressalta que existe diferença entre administração e gestão. Portanto, administrar é planejar, organizar, dirigir e controlar pessoas para atingir de forma eficiente e eficaz os objetivos de uma organização. A gestão seria valer-se de todas as funções administrativas e conhecimentos (psicologia, antropologia, mercadologia, entre outros) necessários pessoas atingir os objetivos de uma organização de forma eficiente (Dias, 2002). Dessa forma, gestão é considerada uma atividade complexa, envolvendo a combinação e a coordenação de recursos humanos, físicos e financeiros, para atingir os objetivos de uma empresa (Giles \& Stansfield, 1980).

O surgimento da gestão moderna deve-se aos princípios fundamentais das teorias de Taylor, Fayol, Mayo e Weber e são considerados os pilares da evolução e do desenvolvimento da ciência da gestão (Garcia \& Bronzo, 2000). No século XX, o engenheiro americano Frederic Winslow Taylor, precursor 
da Teoria da Administração Cientifica, apresentou os princípios da administração cientifica e o estudo da administração como ciência, onde preconizava a prática da divisão do trabalho, ressaltando tempos e métodos a fim de garantir os seus objetivos de máxima produção a custo mínimo (Jacobsen \& Neto, 2015). Com a utilização dos princípios do planejamento, do preparo dos trabalhadores, da execução, do desenho de cargos e tarefas e da padronização (Chiavenato, 1993). Apesar das decorrências sociais e culturais em consequência as propostas por Taylor, elas representaram um enorme avanço para o processo de produção em grande escala (Ferreira et al, 2011). O francês, Henri Fayol defendia princípios semelhantes na Europa, baseados na sua experiência na área administrativa. Fayol relacionou 14 princípios básicos que podem ser estudados de forma complementar aos de Taylor (Dusi, 2013). As 5 funções principais da gestão: planejar, comandar, organizar, controlar e coordenar, são os fundamentos da Teoria Clássica defendida por Fayol (Dusi, 2013). Esta teoria considera a obsessão pelo comando, a empresa como sistema fechado e a manipulação dos trabalhadores, é semelhante à administração científica que desenvolvia princípios que buscavam explorar os trabalhadores (Chiavenato, 2003). Segundo Ferreira et al (2011) existe um paralelo entre a administração Científica e a Clássica, onde Taylor estudava a empresa privilegiando as tarefas de produção e Fayol estudava privilegiando as tarefas da organização. A abordagem dada pelo primeiro era sobre adoção de métodos racionais e padronizados e máxima divisão de tarefas, enquanto o segundo enfatizava a estrutura formal da empresa e a adoção de princípios administrativos pelos altos escalões (Shultz, 2016).

Elton George Mayo, o criador da Teoria Das Relações Humanas, com a Teoria do Comportamento Organizacional provocou o movimento de reação e de oposição à teoria clássica de administração, voltando o foco nas pessoas (Ferreira et al, 2011). Esse movimento teve como origem: a necessidade de humanizar e democratizar a administração, o desenvolvimento das chamadas ciências humanas (psicologia e sociologia), as ideias da filosofia pragmática de John Dewey e da Psicologia Dinâmica de Kurt Lewis e as conclusões do Experimento de Hawthorne, ressaltando que o nível de produção era resultante da integração social, do comportamento social do empregado, da formação de grupos informais, das relações interpessoais, da importância do conteúdo do cargo e ênfase nos aspectos emocionais (Chiavenato, 2003).

A partir de 1950 foi desenvolvida a Teoria Estruturalista, buscavam a conciliação das teses das teorias (Clássica e das Relações Humanas), desdobrada pelos autores da Teoria da Burocracia de Max Weber, a qual se baseava na racionalidade, isto é, na adequação dos meios aos objetivos (fins) para que se obtenha o máximo de eficiência (Ferreira et al, 2011). As principais características de Max Weber foram: a Divisão do trabalho (definição clara da autoridade e responsabilidade), seleção de pessoal com base em qualificações técnicas, hierarquia da autoridade, aplicação de regras e procedimentos para todos, registo de decisões e de atos administrativos e separação entre a gestão e a posse da propriedade (Santos, 2017). Portanto, as teorias defendidas por Taylor, Fayol, Max Weber, Mayo, e dentre outros não citados como, Maslow, Mc Gregor, Barnard e, Lawrence e Lorsch, contribuíram significativamente para a evolução da gestão (Pizolotto \& Silva, 2012).

Atualmente, a gestão é o processo de determinação e orientação do caminho a ser seguido para a realização de seus objetivos compreendendo um conjunto de decisões, liderança, motivação, avaliação e análises (Chiavenato, 1995; Ferreira et al, 2011). Dessa forma, a determinação de metas ou objetivos claros a serem atingidos na empresa precisam ser especificas, mensuráveis e alcançáveis com os recursos disponíveis (ABCS, 2013). Segundo Souza et al (2011), a definição de metas de produtividade a serem atingidas e a forma como os dados são anotados e organizados, dão a clareza sobre a obtenção ou não das metas traçadas, ressaltando também que a avaliação e acompanhamento de indicadores de produtividade e da obtenção de bons índices produtivos, baseados em dados reais, são fundamentais para o sucesso da granja de suínos.

Diante disso é importante que haja uma gestão adequada do sistema produtivo da granja e que sejam implementados métodos/ferramentas de gestão que atenda os objetivos da empresa. Além disso, a administração da produção é fundamental para cada área de uma empresa, pois somente a partir de uma administração bem-sucedida de pessoas, capital, informação e materiais, é possível cumprir suas metas (Lorenzon \& Diedrich, 2019). 


\section{Métodos ou ferramentas de gestão na suinocultura}

Nas últimas décadas, as empresas têm buscado a melhoria dos seus processos de produção e resultados, o que está diretamente relacionada com a lucratividade (Sebrae, 2016). Como qualquer empresa, a suinocultura necessita de um bom gerenciamento devido as características do setor (venda de commodity) e por causa das oscilações de preço do suíno (Agroceres, 2016). Diante disso, as ferramentas de gestão são recursos que servem para auxiliar os gerentes a organizar o trabalho e gerenciar a produção, seja por softwares ou metodologias de gestão (Lorenzon \& Diedrich, 2019).

Mussoi Junior. (2009) enfatiza que os softwares de gestão (programas computacionais) são ferramentas que auxiliam no gerenciamento de dados em todas as fases produtivas na suinocultura, com a opção de criar controles que podem ser aplicados nas formas personalizadas ou individualizadas a cada sistema, além de monitorar mensalmente dados da produção: conversão alimentar, percentual de mortalidade, ganho de peso diário (GPD), consumo de medicamentos e associar essas variáveis, verificando possíveis interações no tempo.

As ferramentas de gestão mais indicadas para serem utilizadas no processo de gestão, buscando uma maior eficiência são: folha de verificação, estratificação, histograma, brainstorming, carta de controle, PDCA, Diagrama de Ishikawa, Diagrama de Pareto e 5W2H (Dellaretti, 1996). Entretanto, destacam-se quatro ferramentas de fácil aplicação na suinocultura: PDCA, Diagrama de Ishikawa, Gráfico de Pareto e 5W2H. Na suinocultura, o método de gestão PDCA (Figura 1) é amplamente utilizado na prática de controle e o cumprimento de metas na produção. Essa ferramenta permite ao produtor ou gerente gerir seus negócios por algumas etapas que compreendem: PLAN (planejamento), DO (execução), CHECK (verificação) e ACT (atuação) (Agroceres, 2016).

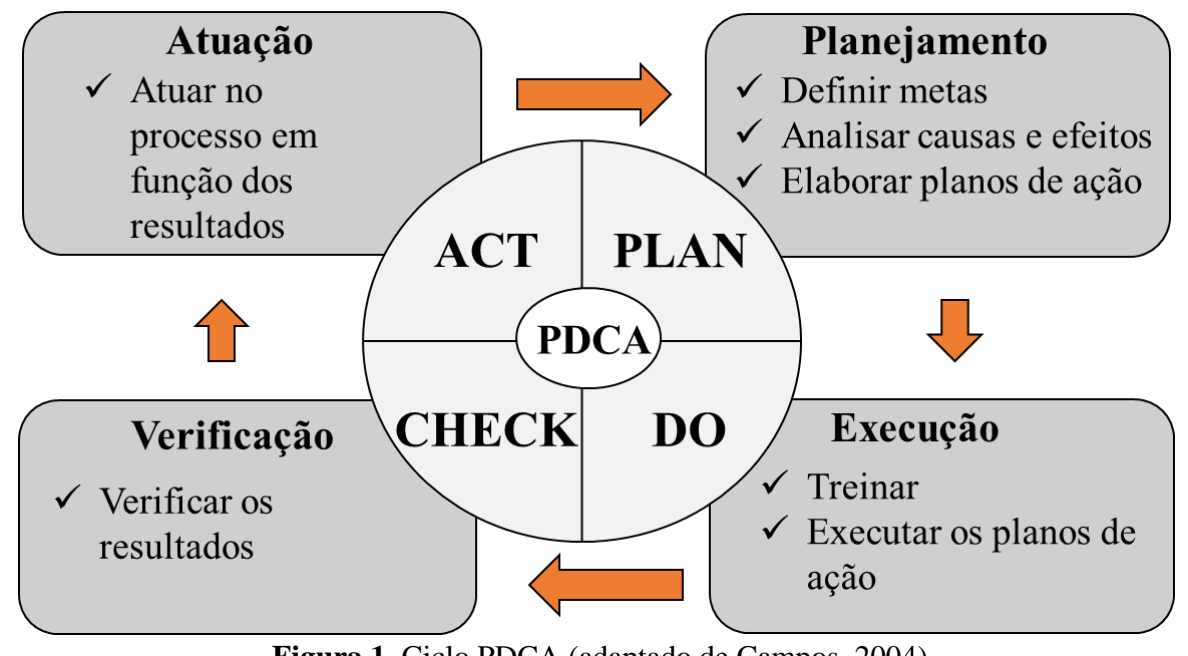

Figura 1. Ciclo PDCA (adaptado de Campos, 2004)

Costa (2018), seguindo a metodologia do PDCA pode observar as causas do problema de anestro em fêmea suína com 190 dias de idade, identificando falhas de manejo referentes à indução a puberdade: alojamento de machos próximos das leitoas, uso de macho (com baixo libido, com problemas locomotores, idade inferior a 10 meses), número insuficiente de machos aptos para serem empregados na estimulação, falta de rotação de machos, tempo insuficiente de contato completo do macho com cada leitoa. Segundo o autor, com a elaboração e execução de um plano de ação e treinamento da equipe, a análise dos resultados sendo positiva na redução do problema, padroniza-se o manejo.

Outra ferramenta é o Diagrama de Ishikawa ou espinha de peixe (Figura 2) também conhecido como diagrama de causa e efeito, muito utilizado quando necessita reconhecer e explorar possíveis causas de um problema ou fatores que estão afetando o processo (Araújo, 2006). A exemplo do uso na suinocultura, Silva (2015) ao analisar a meta da granja em relação ao número de desmamados/fêmea/ano (DFA), isolou todos os fatores relacionados aos manejos reprodutivos e na maternidade, procedimentos e equipamentos que podem interferir na meta, numa relação de causa e efeito. 
O Gráfico de Pareto é uma ferramenta que busca a origem do problema, representado em forma de gráfico (Campos, 2004). Este está baseado no Princípio de Pareto ou a regra dos 80/20, significando que $80 \%$ dos problemas são ocasionados por $20 \%$ das causas, ou seja, são poucas causas que originam a maioria dos problemas. Permitindo uma visualização estruturada dos dados, levando em consideração a importância de cada, de forma a mencionar e diferenciar os problemas que deverão ser resolvidos, bem como sua prioridade (Araújo, 2006).

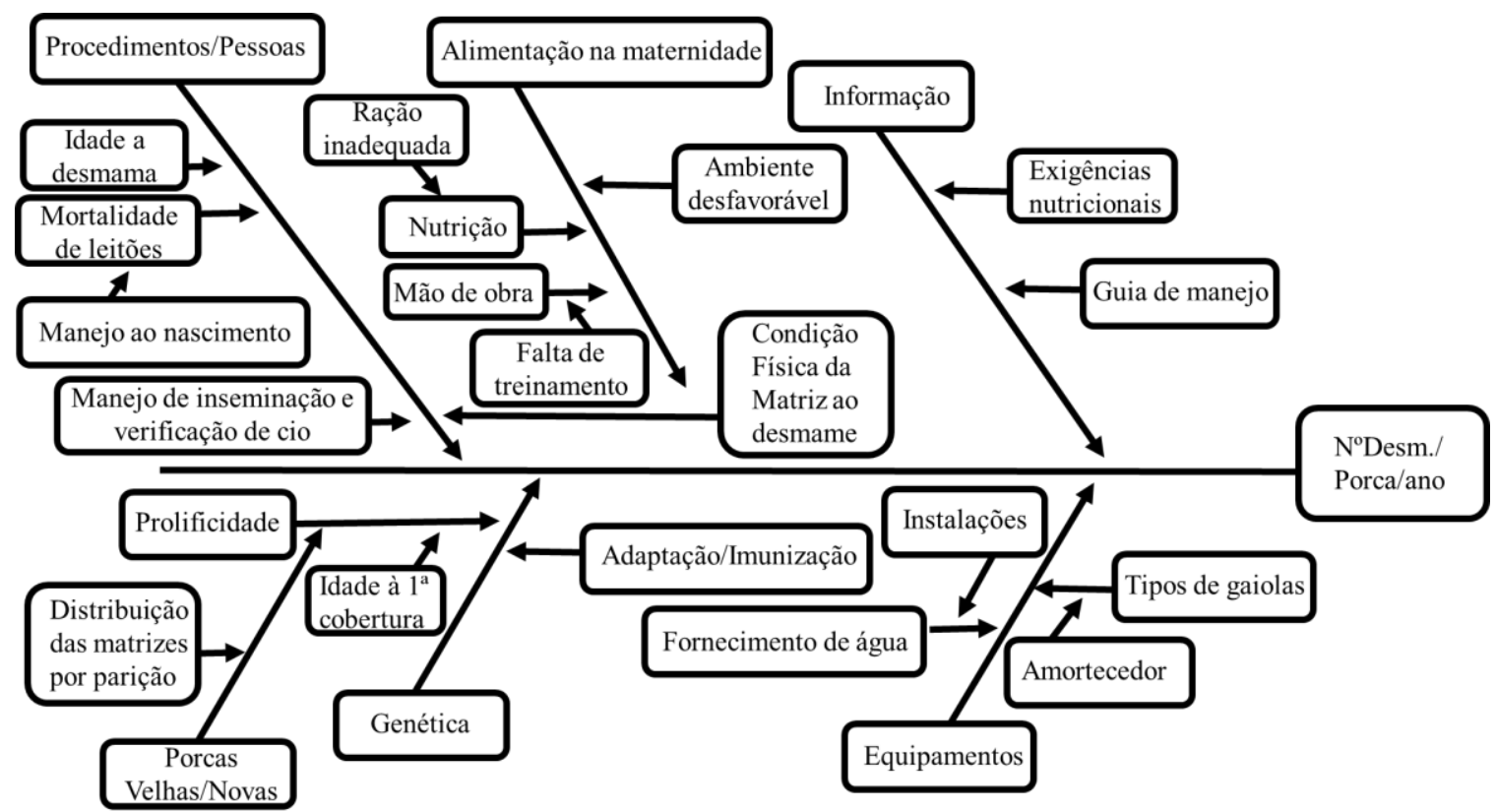

Figura 2. Diagrama de Ishikawa para correlação do efeito e suas causas, adaptado de Silva (2015).

Silva et al. (2010), ao avaliar possíveis causas de poluição ambiental causadas pelas atividades suinícola, utilizando da ferramenta de melhoria contínua, o Gráfico de Pareto (Figura 3). Atribuindo pontos aos problemas ou falhas identificadas (escala de 0 a 6) de acordo com a intensidade de contribuição. Pôde identificar que a contaminação dos recursos naturais é o fator de maior relevância.

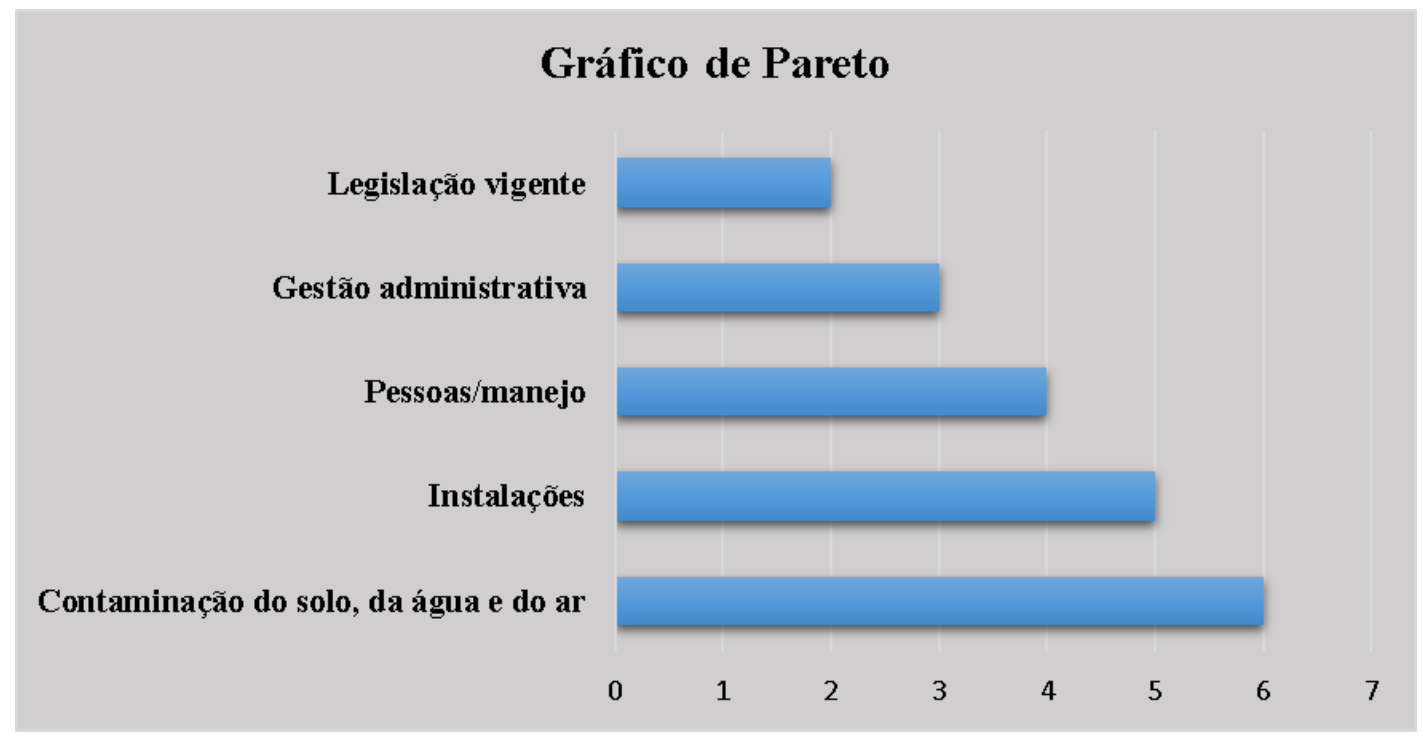

Figura 3. Gráfico de Pareto, adaptado de Silva et al (2010).

O método 5W2H (Figura 4) consiste basicamente em fazer perguntas no sentido de se obter as informações primordiais que servirão de apoio ao planejamento de uma forma geral (Daychoum, 2013). É uma ferramenta de fácil entendimento, estrutura o pensamento de forma organizada e materializada para a tomada de decisão na resolução das não conformidades e oportunidades de melhoria (Werkema, 
1995). Conforme Machado \& Viegas (2012), 5W2H atribui clareza as atividades por meio do planejamento, por escrito, dos detalhes das atividades, eliminando as dúvidas, interferências e duplicidades de interpretação que possam ser geradas no decorrer do processo de implantação das ações. A ferramenta $5 \mathrm{~W} 2 \mathrm{H}$ é uma das mais fáceis de ser implementada e traz grandes benefícios para os gestores e suas atividades organizacionais (Werkema, 1995).

\begin{tabular}{|c|c|c|c|c|c|c|}
\hline \multicolumn{7}{|c|}{ PLANO DE AÇÃO } \\
\hline \multicolumn{7}{|c|}{ Setor: Gestação } \\
\hline \multicolumn{7}{|c|}{ Objetivo: Adaptação das fêmeas ao novo sistema de gestação } \\
\hline \multicolumn{5}{|c|}{$5 \mathrm{~W}$} & \multicolumn{2}{|r|}{$2 \mathrm{H}$} \\
\hline $\begin{array}{l}\text { What? O } \\
\text { QUE? } \\
\text { (Ação a } \\
\text { executar) }\end{array}$ & $\begin{array}{c}\text { Who? } \\
\text { QUEM? } \\
\text { (Pessoa } \\
\text { responsável) }\end{array}$ & $\begin{array}{l}\text { When? } \\
\text { QUANDO? } \\
\text { (Tempo) }\end{array}$ & $\begin{array}{l}\text { Where? } \\
\text { ONDE? } \\
\text { (Local) }\end{array}$ & $\begin{array}{c}\text { Why? POR } \\
\text { QUE? } \\
\text { (Justificativa) }\end{array}$ & $\begin{array}{l}\text { How? COMO? } \\
\text { (Metodologia) }\end{array}$ & $\begin{array}{c}\text { How Much? } \\
\text { QUANTO? } \\
\text { (Custo/investimento) }\end{array}$ \\
\hline $\begin{array}{l}\text { Manejo } \\
\text { das } \\
\text { fêmeas } \\
\text { em } \\
\text { sistema } \\
\text { de } \\
\text { gestação } \\
\text { coletiva. }\end{array}$ & $\begin{array}{l}\text { Funcionários } \\
\text { responsáveis } \\
\text { pelo setor. }\end{array}$ & $\begin{array}{c}\text { Inspeção } \\
\text { diária, } \\
\text { estima-se } 3 \\
\text { segundos } \\
\text { por leitoa. }\end{array}$ & $\begin{array}{l}\text { Setor de } \\
\text { Gestação }\end{array}$ & $\begin{array}{c}\text { Normas da } \\
\text { diretiva } \\
\text { 2008/120/CE. } \\
\text { Bem-estar } \\
\text { animal. } \\
\text { Permite a } \\
\text { interação entre } \\
\text { os animais, } \\
\text { redução do } \\
\text { estresse, } \\
\text { redução de } \\
\text { problemas } \\
\text { sanitários e } \\
\text { diminuição de } \\
\text { estereotipias. }\end{array}$ & $\begin{array}{l}\text { Observação dos } \\
\text { animais, do } \\
\text { consumo de } \\
\text { ração e água, se } \\
\text { os animais } \\
\text { locomovem } \\
\text { naturalmente, } \\
\text { presença de } \\
\text { lesões, } \\
\text { escoriações e } \\
\text { aborto, entre } \\
\text { outros. }\end{array}$ & Não estimado \\
\hline
\end{tabular}

Figura 4. Ferramenta 5W2H em forma de tabela, adaptado pelo autor com base aos dados da cartilha do MAPA (2018).

Diante do exposto, as ferramentas ou método de gestão são instrumentos para identificar oportunidades de melhoria e auxiliar na mensuração e apresentação de resultados, visando ao apoio à tomada de decisão por parte do gestor do processo (Machado et al, 2012).

Por meio do acompanhamento desses processos é possível visualizar onde se quer chegar, como fazêlo e como agir caso algo errado aconteça (Agroceres, 2016). Um fator importante desse processo, são os funcionários, pois são os responsáveis pelo atingimento de metas e cabe ao gestor fazer com que cada um deles se sinta motivado e capaz de trazer os melhores resultados (Barreto \& Pereira, 2007). Deste modo, torna-se importante elucidar o processo de gestão de pessoas.

\section{Gestão de pessoa na suinocultura}

É crescente a tecnificação da empresa suinícola, sobretudo no sistema de produção intensiva, resultado da crescente demanda pela carne suína e pelos os avanços nas diversas áreas da produção. Dessa forma, com o aumento do nível tecnológico da granja, a capacidade de gestão e a qualificação da mão de obra são fundamentais no processo de produção suinícola (ABCS, 2013). Além disso, a retenção de funcionários de qualidade tem sido um dos desafios da suinocultura atual (Agroceres, 2016).

O bom desempenho deste setor é resultado do esforço e trabalho de muitos profissionais, que por sua vez, são de fundamental importância ao processo produtivo (Rocha et al, 2007). Nesse contexto, compreender o conceito de líder e equipe pode esclarecer o papel de cada um dentro da empresa. Segundo Lacombe \& Heilborn (2008), líder é a pessoa responsável por direcionar, orientar, treinar e avaliar a equipe. E equipe é definida como um grupo de pessoas que compreende seus objetivos ou metas em comum e está engajado em alcançá-los, de forma compartilhada (Muscovici, 1999; Luecke, 2010).

Nesse cenário, em granjas bem estruturada, as pessoas são treinadas de forma alinhada com a visão da empresa através da motivação, engajamento, meritocracia, bem-estar, assumindo o papel e a responsabilidade de sua função (Agriness, 2018). Por sua vez, o gestor assume papel importante nas relações de trabalho entre os colaboradores (Agroceres, 2016). Portanto, o grande desafio é conseguir 
incentivá-las, motivá-las e fazer como que os objetivos da organização sejam seus objetivos e que o trabalho, além de ser seu sustento, seja seu grande prazer (Barbosa \& Estender, 2014).

O entendimento da cultura organizacional da empresa, do planejamento estratégico da mesma, permite ao gestor alinhar sua equipe de acordo com as competências colaborativas de cada um para atingir os resultados esperados (Melo et al., 2012). E, desenvolver suas habilidades no conhecimento de seus liderados, identificando seus potenciais e suas fragilidades, assim como qualidades, saber ouvir, dar e receber opinião influencia o desenvolvimento da sua equipe, promovendo mudanças que estimulam o seu crescimento (Silva, 2014). Uma equipe altamente eficiente e comprometida deve ser frequentemente treinada e capacitada, adotando ainda ferramentas de gerenciamento que possibilitam a padronização na execução das rotinas, garantindo os melhores resultados na produção suinícola (ABCS, 2011).

O líder deve identificar a maturidade de trabalho e psicológica do colaborador. A maturidade com relação ao trabalho está relacionada com a capacidade técnica, conhecimento, experiência, e a maturidade psicológica estão relacionadas à disposição, motivação e comprometimento para a realização do seu trabalho (Montanari et al, 2011). O líder de sucesso percebe de forma dinâmica as diferentes necessidades de seus colaboradores atuando de forma diferenciada em situações específicas, aliado ao fato dele perceber as suas limitações com relação ao seu gerenciamento buscando de forma contínua o seu aperfeiçoamento técnico e pessoal (Lezana et al, 2001). Entretanto, a motivação está intimamente relacionada com as necessidades pessoais, porém, cada pessoa determina um tipo de necessidade prioritária sobre as demais, e cabe ao gestor identifica-la em cada colaborador (Chiavenato, 2004). Esse processo nem sempre está diretamente associada ao salário, vai desde o simples elogio individual ou perante a equipe, promoção de cargo e função, até a premiação financeira (ABSC, 2011). As características observadas no líder e na equipe de sucesso na suinocultura destacados por diversos autores estão apresentadas de forma resumida na tabela 1.

Tabela 1. Características observadas no líder e na equipe de sucesso na suinocultura

\begin{tabular}{cc}
\hline O bom líder & A boa equipe \\
\hline - Autorresponsabilidade; & - Automotivada; \\
- Atitude de fazer; & - Engajada/Comprometida; \\
- Bom relacionamento interpessoal; & - Atitude de fazer; \\
- Valores e propósitos; & - Papel e responsabilidade; \\
- Rotina de gestão. & - Cultura e alinhamento. \\
\hline
\end{tabular}

Segundo Chiavenato (2004), as pessoas proporcionam a excelência, a qualidade, a produtividade e a competitividade da empresa, além disso, o trabalho em equipe permite a troca de ideias e experiências, intercambiando soluções e o trabalho em conjunto.

\section{Gestão da informação}

A evolução do conhecimento e das tecnologias ao longo do tempo mudou a forma de se produzir, surgindo junto a necessidade de entender como o processo de produção acontecia, pois era fundamental para a lucratividade do negócio (Barbosa, 2008). E na suinocultura não foi diferente, a informação tornou-se a ferramenta principal de ação, com lugar de destaque nas atividades gerenciais e com base para ações estratégicas e administrativas, estruturando as informações de maneira que pudesse acessála de forma rápida, simples e o mais confiável possível (ABCS, 2013). De acordo com Beal (2004), para a eficácia da gestão da informação é necessário que se constitua um conjunto de medidas que permitam o acesso à informação relevante, precisa e com qualidade. Portanto, a informação bem gerida se transforma em um ponto forte para a empresa, como vantagem estratégica e competitiva (Ferreira \& Perucchi, 2011).

Na suinocultura, a gestão da informação e do conhecimento se tornaram fundamentais para a melhoria dos resultados da produção, onde o processo de coleta de dados, organização e sistematização de informações, ferramentas (quadros, relatórios, softwares etc), processos de uso e análise, entre outra ações importantes, são avaliados para a tomada de decisão (Agriness, 2016). Entretanto, dentre os 
maiores problemas enfrentados pela suinocultura está a tarefa de saber lidar com a gestão da informação para tomar as melhores decisões fundamentadas em dados e informações relevantes a produção, garantindo a utilização de todos os recursos disponíveis de forma eficiente (Silva, 2015).

Resumindo, a informação é um conjunto de dados organizados de forma adequada ao entendimento e à utilização pelo ser humano (ABSC, 2013). Os dados obtidos na granja na forma de relatórios regulares e quadros de "gestão a vista", são ferramentas essenciais no processo de construção da informação, além de auxiliar nas atividades dos profissionais (Agroceres, 2016). Diante disso, benchmarking é um instrumento estratégico, pelo qual as organizações procuram desenvolver melhorias no seu processo de gestão, pela troca de experiências com outras organizações que possuem processos semelhantes (Pinto, 2007). Segundo Rodrigues (2000), a origem do Benchmarking veio do termo em japonês "Dantotsu", cujo significado é ser o melhor dos melhores ou obter o maior desempenho empresarial. $\mathrm{Na}$ área da suinocultura brasileira, existe dois principais rankings (Melhores da Suinocultura Agriness e PigChamp) à disposição, para que os produtores possam comparar os seus dados e avaliar a possibilidade de melhoria (Machado \& Dallanora, 2010). Na figura 5, alguns índices zootécnicos das granjas supervisionadas pela Agriness e PigChamp.

\begin{tabular}{|c|c|c|c|c|}
\hline \multirow{2}{*}{ Índice } & \multicolumn{2}{|c|}{ Agriness } & \multicolumn{2}{c|}{ PigChamp } \\
\cline { 2 - 5 } & \multicolumn{2}{|c|}{1555 granjas $^{1}$} & \multicolumn{2}{c|}{340 granjas $^{2}$} \\
\cline { 2 - 5 } & Média Geral & Médias das Melhores ${ }^{3}$ & Média Geral $^{*}$ Médias das Melhores $^{3}$ \\
\hline Taxa de parição (\%) & 87,24 & 93,77 & 83,73 & 90,68 \\
\hline Nascidos totais & 14,21 & 16,28 & 14,22 & 15,44 \\
\hline Nascidos vivos & 13,05 & 14,94 & 12,71 & 13,89 \\
\hline Mortalidade maternidade (\%) & 8,69 & 5,91 & 14,69 & 19,42 \\
\hline Desmamados/leitegada & 11,87 & 14,07 & 11,16 & 12,05 \\
\hline Desmamados/fêmea/ano & 27,99 & 35,16 & 23,82 & 27,63 \\
\hline
\end{tabular}

Figura 5. Comparação dos índices zootécnicos das granjas. ${ }^{1}$ Granjas Brasileiras. ${ }^{2}$ Granjas Norte Americanas. ${ }^{3}$ Agriness: Melhores 10 granjas; PigChamp: Melhores 34 granjas.

Além disso, o benchmarking é um importante instrumento de gestão das empresas, que visa comparar ou ter como referência outros sistemas de produção similares para o estabelecimento de metas de produtividade na suinocultura (Machado, 2013). Segundo a Agriness (2016), com base no benchmarking anual promovido pela empresa, existe uma correlação positiva entre dados de desempenho produtivo e características ligadas à cultura de gestão e características semelhantes entre elas. Dessa forma, foi criado o "Triângulo de Ouro da Gestão" - (Informação, Pessoas e Operação - vértices do triângulo e Planejamento - o núcleo, Figura 6).

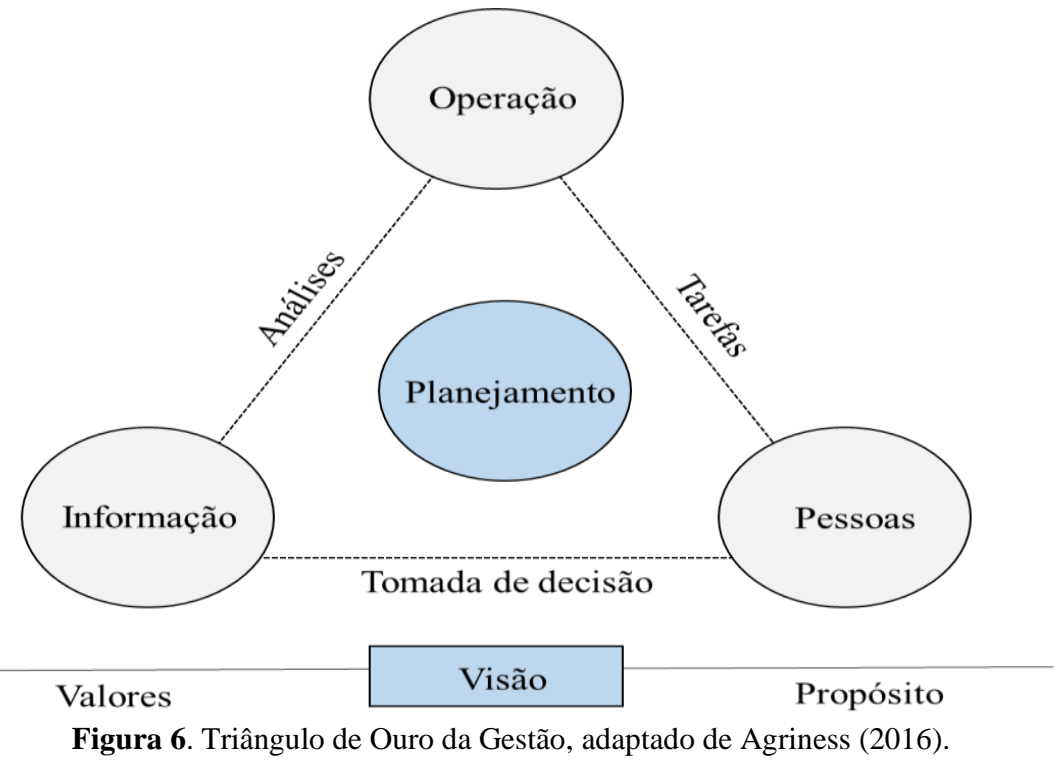


Ainda segundo a Agriness (2016), os bons líderes das granjas de alto desempenho conseguem harmonizar os três vértices do triângulo através de um planejamento bem feito e bem executado. Com isso, a excelência na gestão somente é alcançada com informações e pessoas trabalhando juntas: a informação certa, no momento adequado e para a pessoa correta (Silva, 2015).

\section{Gestão estratégicas dos custos}

A utilização e o desenvolvimento de técnicas de gestão nas granjas suinícolas têm visado basicamente o controle e mensuração dos índices zootécnicos e dificilmente são ofertadas informações sob a óptica financeira (Wernke \& Meurer, 2002). Por isso, é fundamental não somente acompanhar os números de produtividade, mas também saber quanto custou para se produzir (Oliveira \& Filho, 2013).

Lima et al (2010), ao avaliar o custo de produção do kg do leitão aos 63 dias de idade desmamado em diferentes idades (21, 24 e 28 dias), constatou-se que o desmame realizado aos 21 dias de idade apresenta a melhor razão benefício/custo comparado ao desmame feito aos 24 e aos 28 dias e, portanto, seria a idade de desmame mais indicada nas condições que foram realizadas esse estudo. Entretanto, observou-se que a ração fornecida na creche foi item que mais influenciou no custo de produção do leitão aos 63 dias de idade, devendo, portanto, ser levado em conta na tomada da decisão a idade de desmame dos leitões.

O modelo de produção integrada adotado na produção de suínos foi um dos principais fatores que contribuíram para a sustentabilidade e a competitividade deste segmento (Souza et al. 2018). Diante desta realidade, buscam-se prioridade em questões que envolvam a biossegurança, a sanidade, o bemestar animal, o uso racional de antimicrobianos e o investimentos em mão de obra (Schmidt, 2016). Segundo o mesmo autor, existe a necessidade de maiores investimentos em ambiência, principalmente nas fases de gestação e maternidade, considerando a eminente normatização do bem-estar animal no país, pois essa é uma cobrança cada vez mais crescente do consumidor.

Considerando este cenário, o conhecimento dos custos, volume e lucro da atividade pode fornecer relevantes informações quantos aos impactos causados por alterações dos custos de produção, dos preços de comercialização e do volume produzido na granja. Estas informações são consideradas imprescindíveis ao gestor, visto que são constantes as oscilações de preços nos insumos de produção empregados (Wernke \& Meurer, 2002).

Desde modo, o produtor precisa estimar os seus custos fixos e variáveis (Quadro 1), para serem utilizados na análise de rentabilidade da atividade. Os custos variáveis são aqueles que variam de acordo com a quantidade produzida, por outro lado, os custos fixos não variam com a quantidade produzida (Oliveira \& Filho, 2013). E Sousa (2011), define lucro como sendo a diferença das receitas totais da empresa com o montante de custos decorrentes da produção e venda dos bens e serviços.

Quadro 1. Itens dos custos variáveis e custos fixos, adaptado de Embrapa (2018).

\begin{tabular}{|cc|}
\hline Custos variáveis & Custos fixos \\
\hline Alimentação & Depreciação das instalações \\
Mão de obra & Depreciação dos equipamentos \\
Gastos veterinários & Remuneração do capital médio, instalações e equipamentos \\
Gastos com transportes & Remuneração sobre reprodutores e animais em estoque \\
Despesas com energia elétrica & Reposição de reprodutores \\
Despesas com manutenção e conservação & \\
Despesas financeiras & \\
Despesas com aquisição de sêmen & \\
Despesas eventuais & \\
Funrural & \\
\hline
\end{tabular}

$\mathrm{Na}$ análise de rentabilidade, além dos custos citados acima, consideram-se a renda total, margem operacional, margem bruta, lucro e renda líquida. Dessa forma, para que a empresa sobreviva no longo prazo, é necessário que a renda líquida apresente resultado positivo (Oliveira \& Filho, 2013). 
No sistema de integração, as agroindústrias fornecem todos os insumos necessários para a produção no intuito de garantir a obtenção da matéria-prima (suíno) para a transformação final. A receita do suinocultor está atrelada à venda do suíno para a empresa processadora (Ostroski et al. 2006). Dessa forma, os produtores são beneficiados com a segurança na venda dos produtos e garantia da assistência técnica. Todavia, acabam perdendo toda autonomia porque precisa se submeter aos preços estabelecidos pela integradora (Pedroso et al., 2011).

A gestão estratégica dos custos, é uma ferramenta fundamental para manter a rentabilidade do negócio, com uma lucratividade menor, é necessário não somente ganhos em escala, mas também ganhos com eficiência, ou seja, produzir maior volume, com menor tempo e a um custo mais baixo (Oliveira \& Filho, 2013). Muitas empresas de suinocultura têm buscado alternativas em melhorar a produtividade dos animais através da climatização e sistema de alimentação automático. E, biodigestores como forma de reaproveitamento dos resíduos produzidos nas granjas como forma de geração de energia ou crédito de carbono (Silva \& Francisco, 2010). Objetivando aumento da produtividade e o retorno sobre o investimento. Entretanto, o emprego da tecnologia somente deverá ser adotado se os custos decorrentes da sua implementação forem inferiores aos retornos incrementais que ela fornecerá (Oliveira \& Filho, 2013).

\section{Considerações finais}

Com a crescente tecnificação da atividade suinícola, a busca pela sustentabilidade produtiva é constante, para tanto, a gestão precisa acompanhar e adequar suas metodologias de ação, buscando a excelência baseada em dados reais e análises precisas. Deste modo, a informação gerada resultará em

diagnóstico acurado de problemas, culminando em decisões corretivas. É importante ressaltar que são as pessoas envolvidas no processo de produção as responsáveis por todo funcionamento e geração de resultados. Diante disso, a orientação, o treinamento, a motivação e o engajamento de toda equipe envolvida precisam estar alinhada a meta.

\section{Referências Bibliográficas}

ABCS. (2011). - Associação Brasileira de Criadores de Suínos. 2011. Manual Brasileiro de Boas Práticas Agropecuárias na Produção de Suínos/ Elaboração de conteúdo técnico Alexandre César Dias... [et al.]. (1ªed.). Brasília, DF: ABCS; MAPA; Concórdia: Embrapa Suínos e Aves.

ABCS. (2013). - Associação Brasileira de Criadores de Suínos. 2013. Produção de suínos: teoria e prática (1 $\left.1^{\mathrm{a} e d}\right)$. ABCS. Brasília, DF, Brasil.

ABPA. (2018). - Associação Brasileira de Proteína Animal. Relatório Anual 2018. São Paulo, 66-98. Disponível em: <http://abpa-br.com.br/setores/suinocultura/publicacoes/relatorios-anuais >. Acesso: $09 / 10 / 2019$

Agriness. (2016). Um triângulo de ouro na suinocultura de excelência. Agriness Sistemas e Tecnologia de informação ltda.Disponível em: < https://www.agriness.com/pt/triangulo-de-ouro/>. Acesso:18/09/2019.

Agriness. (2018). Relatório anual de desempenho da produção de suínos. $11^{\mathrm{a}}$ edição, 2018. Disponível em: www.melhores.agriness.com. Acesso: 10/11/2019.

Agroceres. (2016). Gestão Enfoco. Agroceres multimix. Disponível em:< https://agroceresmultimix.com.br/blog/category/suinos/>. Acesso: 05/09/2019

Araujo, L. C. G. (2006). Organização, Sistemas e Métodos e as tecnologias de Gestão Organizacional. $2^{\mathrm{a}}$ ed. São Paulo: Atlas.

Barbosa, R. D. S., Estender, A. C. A. (2014). Gestão Estratégica de Pessoas: uma Ferramenta Necessária a Toda Companhia. In: Simpósio de excelência e gestão em tecnologia, 11., 2014. Rio de Janeiro: AEDB. Disponível em: <http://www.aedb.br/seget/arquivos/artigos14/18720144.pdf>. Acesso: 15/09/2019.

Barbosa, R. R. (2008). Gestão da informação e do conhecimento: origens, polêmicas e perspectivas. In: Revista Informação \& Informação, Universidade Estadual de Londrina (UEL), 13,1-25. DOI: http://dx.doi.org/10.5433/1981-8920.2008v13n1espp1. 
Barreto, M. B. B., Pereira, S. L. (2007). A comunicação do líder como fator motivacional. Disponível em: $\quad$ https://portal.tcu.gov.br/biblioteca-digital/a-comunicacao-do-lider-como-fatormotivacional.htm. Acesso: 15/09/2019

Beal, A. (2004). Gestão estratégica da informação: como transformar a informação e a tecnologia da informação em fatores de crescimento e de alto desempenho nas organizações. São Paulo: Atlas.

Campos, V. F. (2004). Gerenciamento da Rotina do Trabalho do Dia-Dia. In: INDG Tecnologia e serviços Ltda, $9^{\mathrm{a}}$ ed., Nova Lima.

Carvalho, E. (2016). Gestão de sucesso na suinocultura. Agroceres multimix. Disponível em: $\langle$ http://www.agroceresmultimix.com.br $>$. Acesso:18/09/2019.

Chiavenato, I. (1993). Introdução à Teoria Geral da Administração. $4^{\mathrm{a}}$ ed. São Paulo: Makron Books.

Chiavenato, I. (1995). Recursos Humanos. São Paulo: Atlas.

Chiavenato, I. (2003). Introdução à Teoria geral da administração: uma visão abrangente da moderna administração das organizações. (7 ed. rev. e atual.), Elsevier, Rio de Janeiro, Brasil.

Chiavenato, I. (2004). Recursos Humanos: o capital humano das organizações. $8^{\text {a }}$ ed. São Paulo: Atlas.

Costa, S. A. (2018). Suinocultura: Avós de suínos. Trabalho de conclusão de curso, atividades do estágio supervisionado obrigatório. Universidade Federal do Paraná. Palotina, Paraná, 2018. Disponível em: https://www.acervodigital.ufpr.br/. Acesso: 10/11/2019.

Daychoum, M. (2013). $40+10$ ferramentas e técnicas de gerenciamento. Rio de Janeiro: Brasport.

Dellaretti, O. F. (1996). As sete ferramentas do planejamento da qualidade. Editora Fundação Cristiano Ottoni, Belo Horizonte, Minas Gerais, Brasil.

Dias, E. P. (2002). Conceitos de gestão e administração: Uma revisão crítica. In: Revista eletrônica de administração. 1 (1).

Drucker, P. F. (1975). Administração: tarefas, responsabilidades, práticas. Management: tasks, responsibilities and practices. Tradução de Carlos A. Malferrari et al. 3. São Paulo: Pioneira.

Duarte, E. N., Silva, A. K. A., Costa, S. Q. (2007). Gestão da informação e do conhecimento: práticas de empresa "excelente em gestão empresarial" extensivas às unidades de informação. Inf. \& Soc.: Est., João Pessoa, 17(1), 97-107.

Dusi, C. S. C. O. (2013). Teorias da Administração. In: Santos, G. J.; Sanábio, M. T. (ed). Administração: princípios teóricos e práticos. Editora UFJF, Juiz de Fora, Minas Gerais, Brasil.

Ferreira, A. A., Reis, A. C. F., Pereira, M. I. (2011). Gestão Empresarial: de Taylor aos nossos dias Evolução e tendências da moderna administração de empresas. São Paulo: Cengage Learning.

Ferreira, T. E. L. R., Perucchi, V. (2011). Gestão e o fluxo da informação nas organizações: a informação no contexto organizacional. In: Revista ACB: Biblioteconomia em Santa Catarina, Florianópolis, 16(2),446-463.

Garcia, F. C., Bronzo, M. (2000). As bases epistemológicas do pensamento administrativo convencional e a crítica à teoria das organizações. In: RODRIGUES, Suzana Braga; CUNHA, Miguel Pina e (Orgs.). Estudos organizacionais: novas perspectivas na administração de empresas (Uma coletânea luso-brasileira). São Paulo: Iglu, 65-89.

Giles, T., Stansfield, M. (1980). The farmer as manager. London; Boston: G. Allen \& Unwin.

Jacobsen, A. L., Neto, L. M. (2015). Teorias da Administração II. 3. ed. rev. amp. - Florianópolis: Departamento de Ciências da Administração - UFSC.

Kruger, S. D., Mazzioni, S., Boettcher, S. F. (2009). A importância da contabilidade para a gestão das propriedades rurais. In: XVI Congresso Brasileiro de Custos. Anais... Fortaleza, CE.

Lacombe, F. J. M., Heilborn, G. L. J. (2008). Administração: princípios e tendências. São Paulo: Saraiva.

Lezana, A. G. R., Pedro, A. M., Ventura, G. F., Camilotti, L. (2001). Liderança: uma habilidade necessária no empreendedor de sucesso. In: Congresso brasileiro de engenharia, Porto Alegre. Anais eletrônico. Porto Alegre: ABENGE, 51-56. 
Lima, L. P., Silva, J. L., Nascimento Junior, N. A.; Melo, D. B. M., Aguiar, S. R. (2010). Custo de produção de leitões aos 63 dias desmamados em diferentes idades. $V$ CONNEPI- Congresso NorteNordeste de Pesquisa e Inovação. Maceió, Alagoas, Brasil.

Lorenzon, E., Diedrich, H. (2019). Utilização do MASP (método de análise e solução de problemas) em uma granja de suínos. Revista Destaques Acadêmicos, Lajeado,11(1). Disponível em: < http://www.univates.br/revistas > Acesso: 09/09/2019

Luecke, R. (2010). Criando equipes. 2. ed. Rio de Janeiro: Record.

Machado, B. S. B., Veigas, M. C. (2012). Estudo de Caso: As Ferramentas da Qualidade Utilizadas no Laboratório de Análises Clínicas de Um Hospital Para a Otimização de Processos, UNOPAR Cient., Ciênc. Juríd. Empres., Londrina,13,75-80.

Machado, G. S., Dallanora, D. (2010). Quais índices devem ser monitorados na gestão de sistemas de produção de suínos. In: Anais do III Simpósio Brasil Sul de Suinocultura e do II BrasilSul Pig Fair. Concórdia:Embrapa Suínos e Aves. 127-146.

Machado, G. S., Dallanora, D. (2013). Evolução histórica dos sistemas de produção de suínos. In: ABCS (ed.) Produção de Suínos: Teoria e Prática. Associação Brasileira de Criadores de Suínos; Coordenação Técnica da Integrall Soluções em Produção Animal- Brasília, DF, Brasil.

Machado, I. P. (2013). Índices zootécnicos e sistemas de gerenciamento na produção de suínos. In: ABCS (ed.) Produção de suínos - teoria e prática. Brasília, DF, Brasil.

Machado, J. R., Rapé, S. F. L., Souza, S. R. (2012). Contabilidade gerencial e sua importância para a gestão e tomada de decisão das empresas contemporâneas. Disponível em: http://www.opet.com.br/faculdade/revista-cc-adm/pdf/n11/ARTIGO-CONTABILIDADEGERENCIAL-OPET.pdf. Acesso: 20/09/2019

MAPA, (2018). Maternidade suína: boas práticas para o bem-estar na suinocultura. Ministério da Agricultura, Pecuária e Abastecimento. Secretaria de Mobilidade Social, do Produtor Rural e do Cooperativismo. - Brasília: MAPA.

MAPA. (2016). Suinocultura de baixa emissão de carbono:tecnologias de produção mais limpa e aproveitamento econômico dos resíduos da produção de suínos / Ministério da Agricultura, Pecuária e Abastecimento. Secretaria de Mobilidade Social, do Produtor Rural e do Cooperativismo. $1^{\mathrm{a}} \mathrm{ed}$. Brasília, MAPA.

Melo, F. A. O., Santos, A. R., Hayashida, M. C. B. P., Machado, T. F. (2012). A influência da gestão de pessoas no desempenho empresarial através do perfil do líder. In: Simpósio de excelência em gestão e tecnologia. Disponível em: https://www.aedb.br/seget/arquivos/artigos12/25416357.pdf. Acesso: $12 / 09 / 2019$

Montanari, R. L., Pilatti, L. A., Lima, I. A., Romano, C. A. (2011). A maturidade e o desempenho das equipes no ambiente produtivo. In: Scielo, Gest. Prod. (online), 18(2),367-378. DOI: http://dx.doi.org/10.1590/S0104-530X2011000200011

Moscovici, F. (1999). Equipes que dão certo: a multiplicação do talento humano. 5 ed. Rio de Janeiro: José Olympio.

Mussoi Jr. E. (2009). Como registrar e usar dados para monitoria de suínos nas fases de recria e terminação. In: Revista Acta Scientiae Veterinariae, 37 (supl. 1): 129-131.

Oliveira, V. F., Filho, J. I. S. (2013). Indicadores econômicos e custo de produção em suinocultura. In: $A B C S$ (ed.) Produção de suínos - teoria e prática. Brasília, DF, Brasil.

Ostroski, D. A., Petry, D., Galina, F. R. (2006). Análise dos modelos de integração suína ciclo completo e terminação: um estudo de caso. Revista Custos e @ gronegócio on line, 2.

Pedroso, S. L., Motta, M. E. V., Pacheco, M. T. M., Camargo, M. E., Gilioli, R. M., Fachinelli, A. C. (2011). Análise de custos e retorno do investimento no sistema de integração em terminação de suínos. Revista PubVet, Londrina, 5(35), 182, 1225.

PigChamp. (2018). Precision Pig Production. Published Dy PigChamp. A Farms. Com company. Disponível em: www.pigchamp.com. Acesso: 10/11/2019.

Pinto, L. F. S. (2007). O homem, o arco e a flecha: Em direção a teoria geral da estratégia. Brasilia: Editora Senac- DF. 
Pizolotto, M. F., Silva, M. (2012). Estudos organizacionais: abordagem estrutural e humanista / Ijuí: Ed. Unijuí, Coleção educação a distância. Série livro-texto.

Rocha, D. T., Moura, A. D., Girotto, A. F., Silva, F. C. O., Veloso, A. F. (2007). Análise de risco de sistemas de produção de suínos, integrado e independente, em períodos de alta e baixa rentabilidade. Revista de Economia e Agronegócio, 5(3), 401-424. DOI: 10.22004/ag.econ.54593

Rodrigues, J. C. D. R. (2000). Técnicas de Gestão Aplicadas nas Organizações. Dissertação (Mestrado)- Universidade São Marcos. Disponível em: $<$ http://professortorg.tripod.com/artigo5.pdf>. Acesso: 25/10/2019.

Santos, L. C. (2017). O Fenômeno Burocrático em Max Weber e Michel Crozier. Dissertação (Mestrado em Sociologia). Universidade Federal do Amazonas, Amazonas, Brasil.

Schmidt, N. S. (2016). Demandas atuais e futuras da cadeia produtiva de suínos. Embrapa Suínos e Aves. Agropensa.

Schultz, G. (2016). Introdução à gestão de organizações. Coordenado pela SEAD/UFRGS. Editora da UFRGS, Porto Alegre, Rio Grande do Sul, Brasil.

Sebrae. (2016). Minha Empresa Sustentável: Suinocultura. Centro Sebrae de Sustentabilidade. Cuiabá, $2016 . \quad$ Disponível em: $<$ https://www.sebraemg.com.br/atendimento/bibliotecadigital/documento/cartilha-manual-oulivro/minha-empresa-sustentavel---suinocultura>. Acesso: 06/09/2019

Serafini, R. F., Ertel, A. L., Schmeling, J. B., Becker, R. T., Guerra, D., Silva, D. M. (2019). Evolução dos sistemas da produção de suínos em uma comunidade rural de Três Passos- RS. Siepex- $9^{o}$ Salão Integrado de Ensino, Pesquisa e Extensão, UERGS, Porto Alegre, RS.

Silva, A. M. R. (2015). Gestão para suinocultura - A importância da gestão de dados na suinocultura. Agriness Academy. Disponível em: < https://academia.agriness.com/wp-content/uploads/2016/05/aimportancia-da-gestao-de-dados-na-suinocultura.pdf>. Acesso: 18/09/2019.

Silva, L. B., Aquino, A. S. M., Sousa, M. M. (2010). Aplicação de ferramentas de melhoria contínua: o caso de uma suinocultura de Urutaí, Goías. Enciclopédia Biosfera, Centro Científico Conhecer. Goiânia, 6 (10).

Silva, N. P., Francisco, A. C. (2010). Geração de energia elétrica a partir de dejetos suínos: um estudo de caso em uma propriedade rural na região oeste do estado do Paraná. In: Revista Nucleus Animalium, 7(2). DOI: https://doi.org/10.3738/nucleus.v7i2.370

Silva, P. M. S. (2014). O papel do líder na motivação da equipe. In: Revista acadêmica da faculdade Osvaldo Cruz, 4(1)12-378.

Sousa, J. M. (2011). Lucro Relacionado ao Conceito de Preservação da Riqueza. Centro de estudo e assessoria pedagógica. Disponível em: 〈http://www.ceap.br/artigos/ART06122007183721.PDF>. Acesso: 15/11/2019.

Souza, H. C., Fehr, L. C. F. A., Trindade, J. A. S., Tavares, M. (2018). Custos de produção de suínos: estudo nos principais estados produtores do Brasil. XXV Congresso Brasileiro de Custos, Vitória, ES, Brasil.

Souza, J. C. P. V. B., Amaral, A. L., Morés, N., Tremêa, S. L., Miele, M., Filho, J. I. S. (2011). Sistema de produção de leitões baseado em Planejamento, Gestão e Padrões Operacionais. Embrapa Suínos e Aves, Concórdia, Santa Catarina, Brasil.

Werkema, M. C. C. (1995). As ferramentas da qualidade no gerenciamento de processos. Fundação Christiano Ottoni, 2 ed., UFMG,Belo Horizonte.

Wernke, R., Meurer, M. (2002). Análise custo/volume/lucro aplicada na suinocultura: Estudo de caso em pequena propriedade catarinense. IX Congresso Brasileiro de Custos, São Paulo, SP, Brasil.

Zen, S. D., Ortelan, C. B., Iguma, M. D. (2014). Suinocultura brasileira avança no cenário mundial. Informativo CEPEA, Análise Trimestral/ Custos de Produção da Suinocultura. Universidade de São Paulo, Escola Superior de Agricultura Luiz de Queiroz.

Recebido: 2 de novembro, 2019.

Aprovado: 1 de fevereiro, 2020.

Disponível online: 17 de junho, 2020.
Licenciamento: Este artigo é publicado na modalidade Acesso Aberto sob a licença Creative Commons Atribuição 4.0 (CC-BY 4.0), a qual permite uso irrestrito, distribuição, reprodução em qualquer meio, desde que o autor e a fonte sejam devidamente creditados. 